The author summarizes the findings from a study of 729 chief academic officers who identify both catalysts and barriers to the reform of faculty reward systems.

\title{
Encouraging Multiple Forms of Scholarship in Faculty Reward Systems: Have Academic Cultures Really Changed?
}

\author{
KerryAnn O’Meara
}

\begin{abstract}
The nation's higher education institutions have increasingly become more imitative than distinctive. . . Campuses increasingly seek to gain status by emulating research centers... resulting in many institutions losing a sense of distinctiveness and scholarship's potential remaining strikingly unfulfilled.

-Boyer (1990, p. 54)
\end{abstract}

Concerned that higher education institutions were losing their distinctiveness in the pursuit of prestige, Ernest Boyer (1990) argued that institutions should return to their roots and reward faculty involvement in the teaching, integration, and application of knowledge as well as in research. He also argued that faculty reward systems should stress the forms of scholarship most closely aligned with their institutional mission (baccalaureate institutions, for example, should stress teaching scholarship). Boyer asserted that if formal changes were made to reward systems to encourage the discovery and

Thanks to Jeff Hauger, a doctoral candidate in the Research and Evaluation Methods Program at UMass Amherst, for his work as a research assistant, Gene Rice for his involvement in and support of this research, and John Braxton for his editorial work on this chapter and invitation to share this work here.

\section{(4)WILEY}

\section{InterScience}


teaching, integration, and application of knowledge, there would be greater acceptance and appreciation of these multiple forms of scholarship by faculty and administrators and greater alignment between faculty rewards and institutional mission. In other words, baccalaureate institutions with primary teaching missions would reward the scholarship of teaching in their promotion decisions and not hold faculty back because they were not engaged in the same type of work as research faculty. Doctoral institutions might acknowledge the scholarship of application in promotion and tenure decisions, and the work of faculty in many master's institutions in developing interdisciplinary programs (the scholarship of integration) would not go unrecognized.

Hundreds of campuses nationwide and abroad have changed their promotion and tenure language and put other structures in place to encourage and reward multiple forms of scholarship since 1990 (Berberet, 2002; Brailow, 2005; Diamond, 1999; Glassick, Huber, and Maeroff, 1997; O'Meara, 1997, 2002; Rice and Sorcinelli, 2002; Zahorski, 2005). Yet very little empirical research has been conducted to see if academic cultures have really changed. This is a growing area of study as scholars and academic leaders try to understand the extent of reform in faculty roles and rewards prompted by Scholarship Reconsidered (Berberet, 2002; Braskamp, 2003; Braxton, Luckey, and Holland, 2002; Huber, 2002; O'Meara, 2002). For example, Braxton, Luckey, and Holland (2002) explored faculty professional performance to understand the degree to which faculty in four disciplines had institutionalized the four domains of scholarship in their everyday work. They found that all four domains of scholarship had attained the most basic or structural-level institutionalization, the scholarships of discovery and teaching had attained procedural-level institutionalization (wherein the activity is a regular part of workload), but only the scholarship of discovery achieved incorporation-level institutionalization (faculty values and assumptions support the activity).

I conducted case study research to understand the impact of redefining scholarship in four institutions and found that each of the four campuses that reformed their promotion and tenure policies experienced a slightly more balanced reward system, an increase in faculty involvement in alternative forms of scholarship, and greater faculty satisfaction with their institutional work life. The Carnegie Foundation's 1997 national survey of college and university faculty explored the emphasis put on different forms of scholarship over the previous five years and found that nearly half the faculty at research universities said greater emphasis was being placed on teaching than five years before (Huber, 2002).

Given the hundreds of campuses that reformed their reward systems as Boyer (1990) and others (Diamond, 1993, 1999; Glassick, Huber, and Maeroff, 1997; Lynton, 1995; Rice, 1996) suggested, additional research is needed to explore whether these reforms resulted in the culture change that was predicted. If so, what forces supported the change, and what forces thwarted it? 


\section{Framework for This Study}

This study was guided by the literature on organizational change and organizational culture in higher education systems (Bergquist, 1992; Bolman and Deal, 1997; Eckel, Green, Hill, and Mallon, 1999; Kezar, 2002; Kuh and Whitt, 1988; Schein, 1992) and on faculty roles and rewards (Blackburn and Lawrence, 1995; Boyer, 1990; Diamond, 1999; Rice, 1996; Rice and Sorcinelli, 2002). In addition, research and literature discussing the important differences across institutional types informed this work (Clark, 1987; Finnegan and Gamson, 1996; Prince, 2000; Ruscio, 1987; Ward and Wolf-Wendel, 2004).

Over the past ten years, many forces have pushed institutions to establish a closer balance among teaching, research, and service in reward systems and to support multiple forms of scholarship (Diamond, 1993, 1999; Lynton, 1995; Rice, 1996; Rice and Sorcinelli, 2002). In addition, many barriers to change have been identified in studies of academic reward systems (Braxton, Luckey, and Holland, 2002; Eckel, Green, Hill, and Mallon, 1999; Kezar, 2002; Rice and Sorcinelli, 2002). For example, research has shown the important role that leaders such as chief academic officers (CAOs), department chairs, and deans play in promotion and tenure systems and in how scholarship is defined, assessed, and rewarded (Eckel, Green, Hill, and Mallon, 1999; Tierney and Bensimon, 1996). An institution's history and culture of valuing or not valuing teaching as a scholarly activity will greatly influence whether a new reform naming teaching as scholarship will be accepted (Huber, 2002). Rice (1996, p. 8) observes that the "assumptive world of the academic professional," which values independent basic research over applied and collaborative work, has a significant influence on faculty roles and rewards in almost all institutional types. External pressures from invisible colleges, parents, or accrediting agencies have been found to be important forces for change (Birnbaum, 1988; Eckel, Green, Hill, and Mallon, 1999). Bolman and Deal (1997) have suggested that human resource, structural, political, and cultural and symbolic forces often thwart change and reform. Thus, research on organizational culture and change in faculty roles and rewards suggests three categories of relevant catalysts in reforming reward systems to encourage multiple forms of scholarship: external pressures, cultural elements, and leadership. Bolman and Deal's four frames-structural, human resource, political, and symbolic_categorize the barriers.

How individuals make meaning of change within academic communities will be influenced by their role (faculty member, department chair, dean), discipline, career stage, and institutional type. While research suggests that some subgroups may be more likely to embrace a broader definition of scholarship than others, real change must penetrate the entire institution (Bergquist, 1992; Eckel, Green, Hill, and Mallon, 1999; Kezar, 2002; Kuh and Whitt, 1988). Accordingly, it is important to understand the 
pockets of support or resistance among institutional subcultures defined by academic role, discipline, and career stage.

The movement to reward multiple forms of scholarship has meant different things at different types of institutions. Many research universities have reformed their reward system as Boyer suggested to elevate the status of the scholarship of teaching, while many liberal arts colleges have tried to alter a culture focused on teaching and institutional service to one that rewards teaching as a form of scholarship and also encourages discovery and integration (Huber, 2002; O'Meara, 2005a; Zahorski, 2005). Thus, in framing the research and analyzing the data, I considered the starting points of different institutional types with regard to faculty roles and rewards (Braxton, Luckey, and Holland, 2002; Clark, 1987; O'Meara, 2005a; Ward and Wolf-Wendel, 2004).

This study had three guiding research questions:

- What are the catalysts to reform?

- What are the barriers to reform?

- Does making formal policy changes to encourage multiple forms of scholarship increase acceptance of this work by different campus constituents?

\section{Methodology}

Chief academic officers play a critical role in ensuring the integrity and fairness of the faculty evaluation process and promoting growth and morale among members of the faculty (Diamond, 1993). Perhaps most important, their position requires them to have a bird's-eye view of their institution, its history, and its existing and future directions in terms of faculty roles and rewards. CAOs must constantly negotiate the strengths and weaknesses of their academic cultures and thus are likely to have a good sense of current values and beliefs regarding scholarship. Because of their pivotal role in setting standards for and assessing faculty work and because of their ability to describe what has happened and is happening in faculty roles and rewards across their campuses, CAOs are the ideal participants for this study.

Survey research was the preferred method of data collection because little research has explored this area and it provided a vehicle to do initial exploratory research and generalize from a sample to the larger population of CAOs at four-year institutions (Fowler, 1993). The survey questions explored CAO perceptions of how their academic cultures affected and were affected by formal policy changes. Survey items were developed directly from the literature review. The methodology placed institutions into two groups: those that did and did not make relevant formal policy changes that encourage multiple forms of scholarship. Such policy changes include expanding the written definition of scholarship in mission state- 
ments, planning documents, faculty evaluation policies, flexible workload programs, and incentive grants. These were the most common reforms made and the mostly highly advocated in the review of best practices literature and in campus studies. CAOs at institutions that had made one or more of these formal changes to their reward systems within the past ten years are referred to as reform CAOs, and CAOs at institutions that did not make formal changes over the previous ten years are referred to as traditional CAOs.

Approximately two-thirds of CAOs completed the survey online, responding to an e-mail invitation to complete a Web-based survey, while the remaining one-third completed a paper copy mailed to them. The results reported here are based on the responses of 729 (50 percent) of the CAOs or their designees of the 1,452 nonprofit four-year colleges and universities identified by the 2000 Carnegie Classification system. These survey responses are representative of the national profile of institutions when compared to the 2000 Carnegie Classification of four-year nonprofit institutions. The majority of CAOs, 498 (68 percent), reported that their institutions had made formal changes to their reward system over the past ten years; 231 (32 percent) reported that their institutions had not.

For the purposes of this research, a decision was made to collapse several Carnegie (2000) categories into three major institutional-type categories: research and doctoral institutions, master's institutions, and baccalaureate institutions. These categories represent three different types of potential responses to the Boyer reform for comparison, as the missions of these institutional types are distinct. Clearly there are significant differences between how public and private, selective and nonselective, religiously affiliated, historically black colleges and universities, two-year institutions, and others consider and reward scholarship (Clark, 1987). In addition, prestige makes a significant difference in institutional context and culture (Kuh and Pascarella, 2004). The fact that the data in this study are not further broken down by these categories is not to say these distinctions are not important, just beyond these space considerations. These distinctions are important to study in subsequent research.

The survey data were analyzed using descriptive statistics and multivariate statistics. In most cases, independent samples $t$-tests were conducted to compare reform and traditional CAOs' answers to survey questions, considering reform CAOs as the reference group. A one-way ANOVA was performed to determine the differences between institutional type and CAOs' answers to the survey questions. Independent chi-square tests were conducted when the dependent variables were categorical variables instead of continuous variables. The chi-square tests were used to determine if there was a significant association between the characteristics of the population. The alpha level was determined to be .05 for all of the analyses calculated. 


\section{Findings}

The descriptive statistics from survey findings on catalysts and barriers were reported in previous research but not examined by institutional type. All other data are presented here for the first time. (See O'Meara, 2005a, 2005b, for additional description of the methodology, sample, and findings from this survey.)

Degree of Reform and Types of Reform. The survey responses noting "reform" or "traditional" were analyzed across institutional type using descriptive statistics first. The responses are as follows:

Reform: Doctoral/research, 18 percent; master's, 46 percent; baccalaureate, 36 percent

Traditional: Doctoral/research, 21 percent; master's, 35 percent; baccalaureate, 44 percent

A one-way ANOVA on institutional type $(F=3.20 ; p<.05)$ produced significant differences because of the higher percentage of reform master's colleges ( 46 versus 35 percent traditional) and a much lower percentage of reform baccalaureate colleges (35 versus 44 percent traditional).

Reform CAOs (68 percent of the total sample) were asked which types of reform their institutions had made in the past ten years. They could check any of the four types of reform listed but had to check or not check each item; thus, the number of times each reform was checked by respondents is the underlying metric for results reported in Figure 6.1. When the types of reform are compared across the three institutional types, doctoral/research institutions are significantly more likely than master's and baccalaureate institutions to note their campus had expanded the definition of scholarship written into institutional mission and planning documents and significantly more likely than baccalaureate institutions to note that their campus had used the new definition of scholarship to develop flexible workload policies where faculty could emphasize different forms of scholarship and be evaluated accordingly (see Figure 6.1).

Catalysts to Reform: The Decision to Change Faculty Evaluation Policy. A list of external, cultural and leadership factors was developed from the literature (see Table 6.1), and reform CAOs (68 percent of participants) were asked to rate the extent to which these factors influenced their institutions' decision to reform their reward system to encourage multiple forms of scholarship. Over half of reform CAOs reported that ten of the fifteen factors were a major or minor influence. This suggests that rather than one factor, like the institution's commitment to teaching spurring change, it is the interaction of leadership, mission, and the discussions generated by Scholarship Reconsidered that synergistically sparks reform. I reported these data previously (O'Meara, 2005a) but did not explore the 


\section{Figure 6.1. Types of Reform by Institutional Classification}

Question: Please check each of the statements that describe a change you made in your institution in the last ten years. Expanded definition of scholarship through:

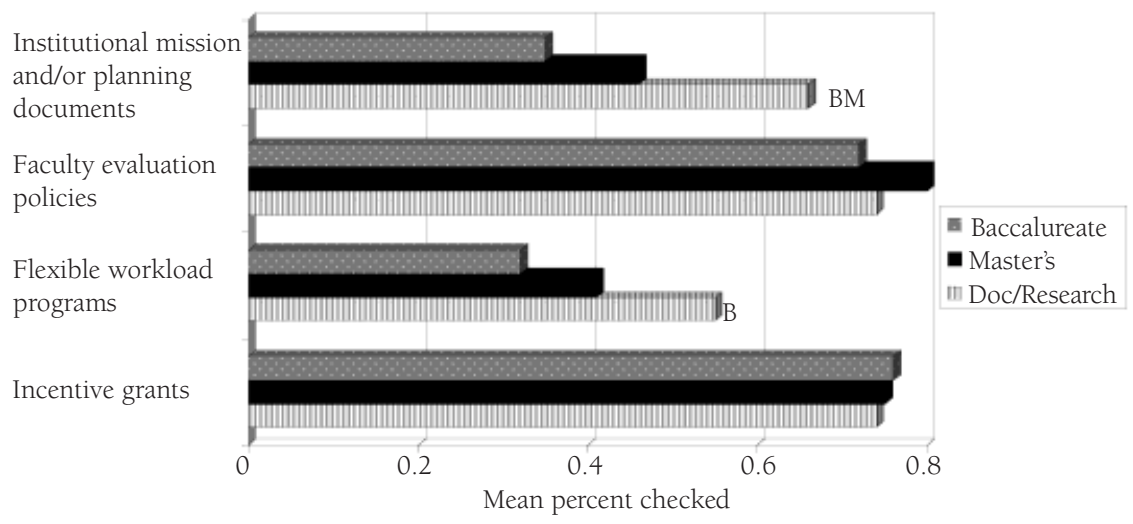

Note: $\mathrm{B}=$ This mean is significantly different from baccalaureate colleges $(p<.05)$.

differences by institutional type. The following three sections group the catalysts by type of factor and then present significant differences across the three major institutional types (Table 6.1).

External Pressures. Five external pressure factors-encouragement from accreditation agencies; ideas generated by Boyer's Scholarship Reconsidered; faculty or administrator involvement in the national movement to redefine faculty roles and rewards; pressures from state legislature, parents, and/or trustees for greater accountability; and partnerships with industry-are significantly more influential for baccalaureate colleges than for master's and doctoral/research universities (depending on the question). These findings are consistent with previous research suggesting the greater vulnerability of baccalaureate institutions to external forces (Clark, 1987). Although there was significant external public pressures on doctoral and research universities in the late 1980s and throughout the 1990s to change their reward systems to be more responsive to undergraduate teaching and outreach demands (Boyer, 1990), it appears that the baccalaureate colleges are the ones that actually responded.

Leadership. Leadership by the institution's president is significantly more influential for baccalaureate colleges regarding the institution's decision to change faculty evaluation policy to encourage and reward multiple forms of scholarship. Also, leadership by the institution's other administrators (besides 


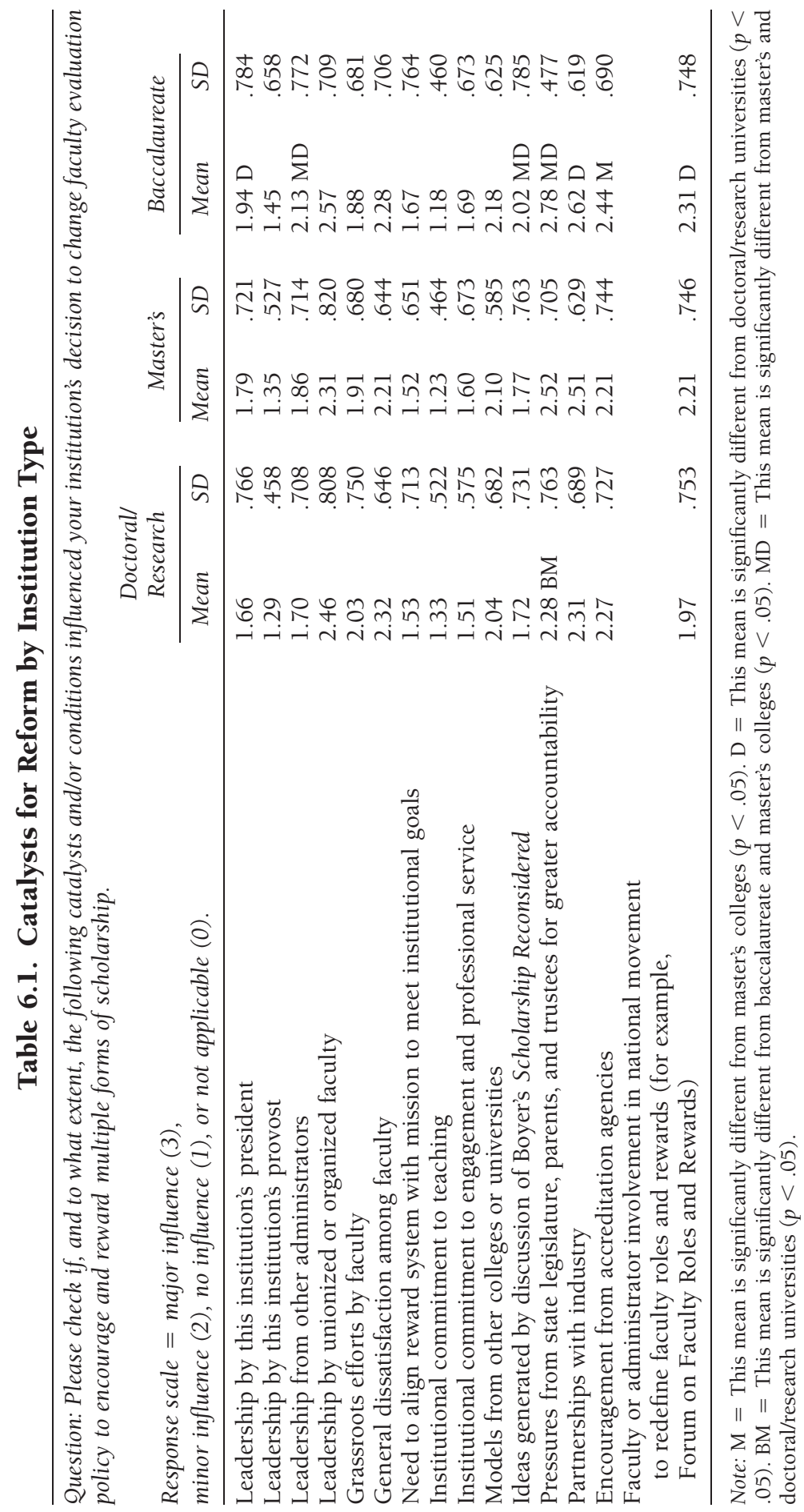


the president and provost) is significantly more influential for baccalaureate colleges regarding the institution's decision to change faculty evaluation policy to encourage and reward multiple forms of scholarship. These findings are consistent with previous research suggesting the greater role of college presidents in internal affairs in smaller liberal arts colleges and the greater external role of presidents in larger doctoral and research universities (Birnbaum, 1992). Likewise, associate provosts and directors of centers for teaching, professional development, honors colleges, and other learning communities (the type of positions likely included in the term other administrators) seem to play a larger role in advocating for reward system change in smaller, more collegial institutions.

Cultural Elements. There are no significant differences among institutional types on the cultural factors of general dissatisfaction among faculty, need to align reward system with mission to meet institutional goals, commitment to teaching, and commitment to engagement and professional service. This is curious given that we might expect the more teaching-oriented institutions to note the institutional commitment to teaching as a catalyst and those more service-oriented master's and doctoral institutions to observe a commitment to service as a catalyst. However, ten of the fifteen factors are noted as major or minor influences by all CAOs-and the factors of general dissatisfaction among faculty (which 50 percent of reform CAOs said was a major or minor influence) and need to align reward systems with mission (which 49 percent of reform CAOs said was a major influence) seem to have been similarly important across institutional types (O'Meara, 2005a). Also, the Boyer reform offered an opportunity for every institution to recommit to the value and scholarship of teaching, and 73 percent of reform CAOs noted the institutional commitment to teaching as a major catalyst. Because the movement to redefine scholarship to include application and engagement was smaller than the movement to recognize teaching and because 44 percent of all reform CAOs noted it was a major influence, this catalyst also seems to have been similarly important across institutional types, albeit less than the institutional commitment to teaching factor.

Barriers to Rewarding Multiple Forms of Scholarship. Just as with catalysts, a list of barriers was developed from the literature. Whereas the catalysts grouped effectively into external, leadership, and cultural factors, the barriers were somewhat more internal, structural, political, and human resource related, so we used the four frames developed by Bolman and Deal (1997) for examining organizational problems and change (see Table 6.2). While the categories may appear tidy, each of the barriers has multiple facets. For example, "insufficient training for department chairs" might be categorized here as a human resource barrier, but it also has structural and political implications. Thus, the categorization is presented more as an efficient way to situate the primary concern in the twenty barriers than as a definitive framework in and of itself. 
Reform CAOs are significantly more likely than traditional CAOs to report the following external, cultural, or leadership forces as barriers: (1) the political nature of faculty evaluation, (2) excessive paperwork for faculty evaluation, (3) insufficient training for department chairs and deans, (4) faculty concerns about unrealistic expectations that they excel in all areas at the same time, and (5) unevenness in applying new criteria and standards within and across units (O'Meara, 2005a). The following sections group the barriers by type of factor and then present significant differences across the three major institutional types examined (Table 6.2).

Structural. Master's and doctoral universities report higher Carnegie aspirations, higher research expectations, and greater pressure from professional disciplines as barriers. Baccalaureates are significantly less likely than master's and doctoral/research universities to find structural barriers related to documenting multiple forms of scholarship for promoting and tenure, expanding a consistent definition of scholarship across the university, and applying new criteria and standards within and across units. Clearly the institutional size of many of the doctoral and research universities makes institutionalization a much more difficult problem for these institutions than the comparably smaller and more homogeneous baccalaureate colleges where, for example, the reward system is more centralized.

Human Resources. Baccalaureate institutions are significantly less likely than master's and doctoral/research universities to find confusion and ambiguity for faculty about what really counts for promotion and tenure. On the other hand, doctoral/research universities are significantly more likely than baccalaureate colleges to note confusion about the definitions of teaching, research, and service as scholarship, and faculty fear that if the reward system changes, faculty careers, and programs will be less marketable or transferable. Again, these findings are consistent with research on institutional size and on faculty roles and rewards in different institutional types: faculty desire to be marketable within their discipline is more of a concern in doctoral/research universities than baccalaureate institutions that are more teaching oriented (Clark, 1987).

Political. Master's colleges are significantly more likely than baccalaureate institutions to note resistance from faculty unions and rejection of the reform because it was initiated by administration, change in institutional priorities, and the political nature of faculty evaluation as barriers. Many master's colleges are state comprehensives with faculty unions and significant teaching loads alongside institutional ambitions for greater research emphasis.

Symbolic and Cultural. The more research oriented an institution is, the more that values and beliefs about scholarship, disciplinary influence, and the nature of faculty careers are significant barriers in trying to implement Boyer reforms. Doctoral/research universities are significantly more likely than baccalaureate and master's colleges to note desire on the part of 


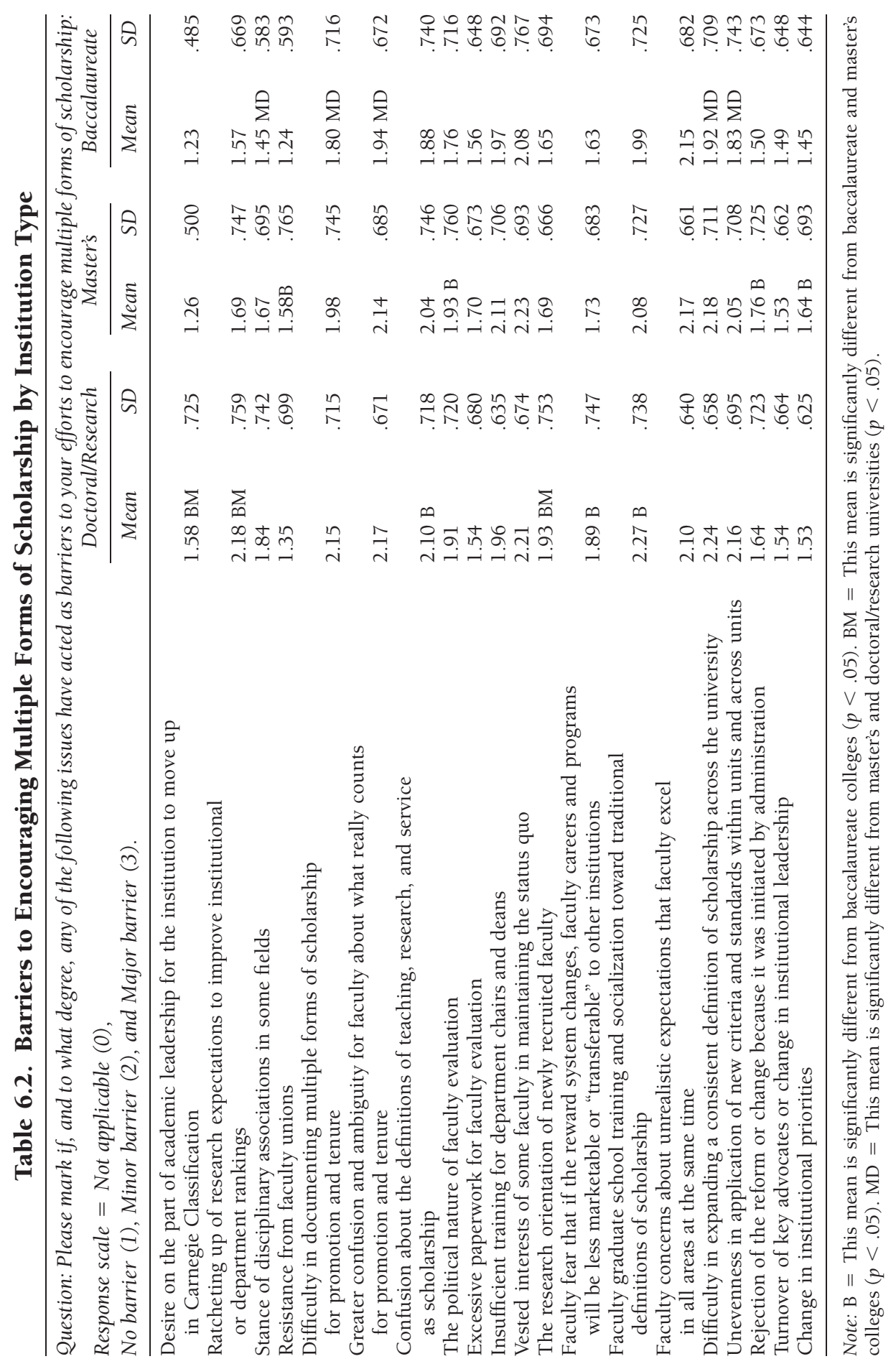


academic leadership to move up in Carnegie classification, ratcheting up of research expectations to improve institutional or departmental rankings, and the research orientation of newly recruited faculty as barriers, and significantly more likely than baccalaureate institutions to find faculty graduate school training and socialization toward traditional definitions of scholarship as a barrier. The less research-oriented baccalaureates face less resistance in redefining scholarship.

Acceptance Within Academic Cultures. All CAOs were asked whether it was commonly believed on their campus that aspects of college teaching, engagement, integrative and interdisciplinary activity, and participatory action research could be defined as scholarship. All CAOs were also asked whether over the past decade they believed their faculty had developed a more complex, nuanced view of scholarship. In every case, independent samples $t$-tests showed that reform CAOs are significantly more likely than traditional CAOs to note these statements as true (see Table 6.3). There are some significant differences when the responses are compared by institutional type. Doctoral/research universities are significantly less likely than baccalaureate and master's colleges to agree that aspects of college teaching, engagement and professional activity, participatory action research, and other forms of newer research might be defined as scholarship on their campuses (Table 6.3).

All CAOs were also asked to rate the level of support for an expanded definition of scholarship among groups by discipline, career stage, and administrative role during the past five years (Figure 6.2). In every case, reform CAOs are significantly more likely than traditional CAOs to rate the constituency (whether social science faculty, midcareer faculty, or dean) as supportive or very supportive.

\section{Discussion and Implications}

The findings presented here suggest at least two implications for our understanding of the impact of Boyer's (1990) reforms on academic cultures and reward systems.

First, institutional type, culture, and constraints on faculty work should be considered when initiating these reforms in academic reward systems. The particular circumstances of each institutional type play a large role in why the institution decided to initiate reform to its reward system and the special barriers it found to implementing the reforms. Baccalaureates are more likely to be influenced by internal leadership (for example, the president and provost) and from external pressures (for example, accreditation, industry partnerships) than the other two types. Master's colleges are very likely to have made reforms but faced resistance from unions likely afraid of adding responsibilities to already full faculty plates by encouraging multiple forms of scholarship. The need to compete in the research prestige 


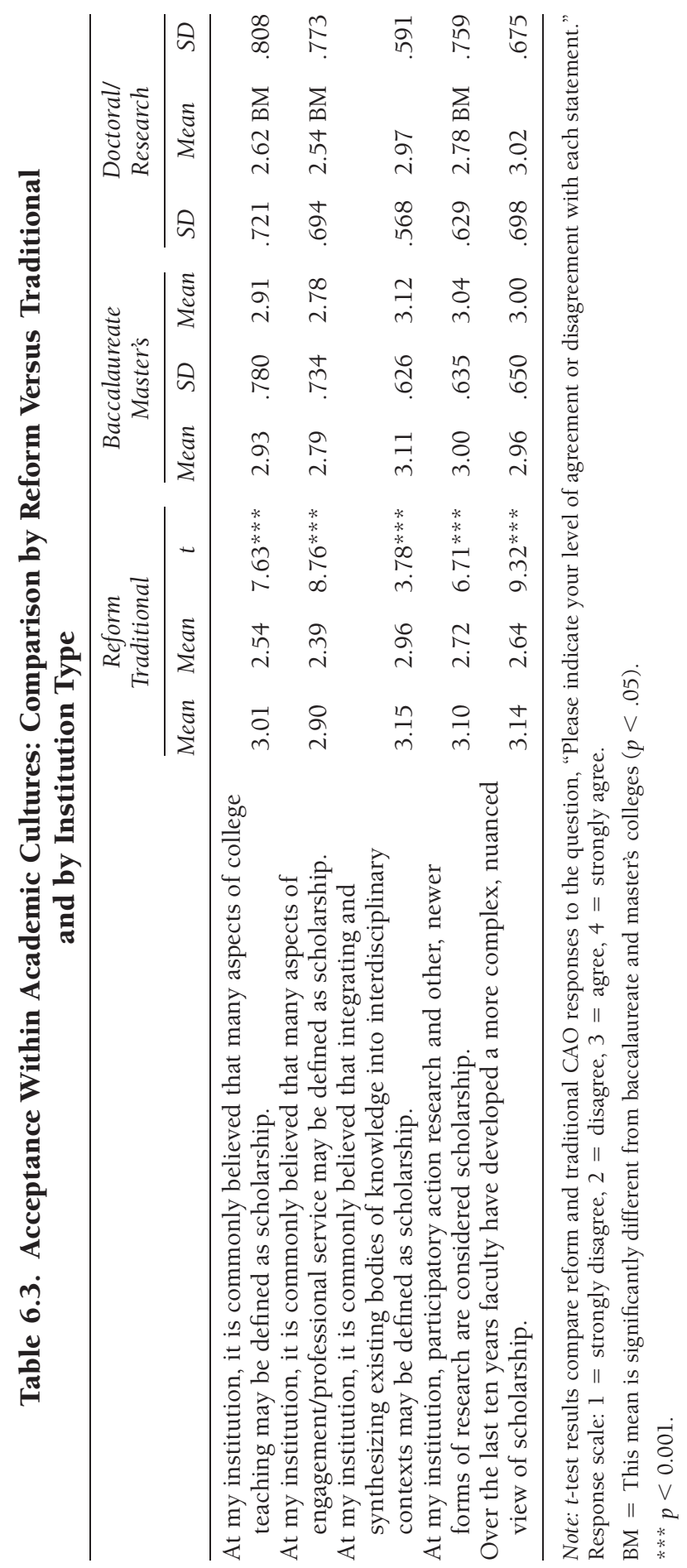


Figure 6.2. Results of $t$-Test Comparing Reform and Traditional CAO Responses to the Question: "How would you rate the level of support for an expanded definition of scholarship among the following groups during the past five years?"

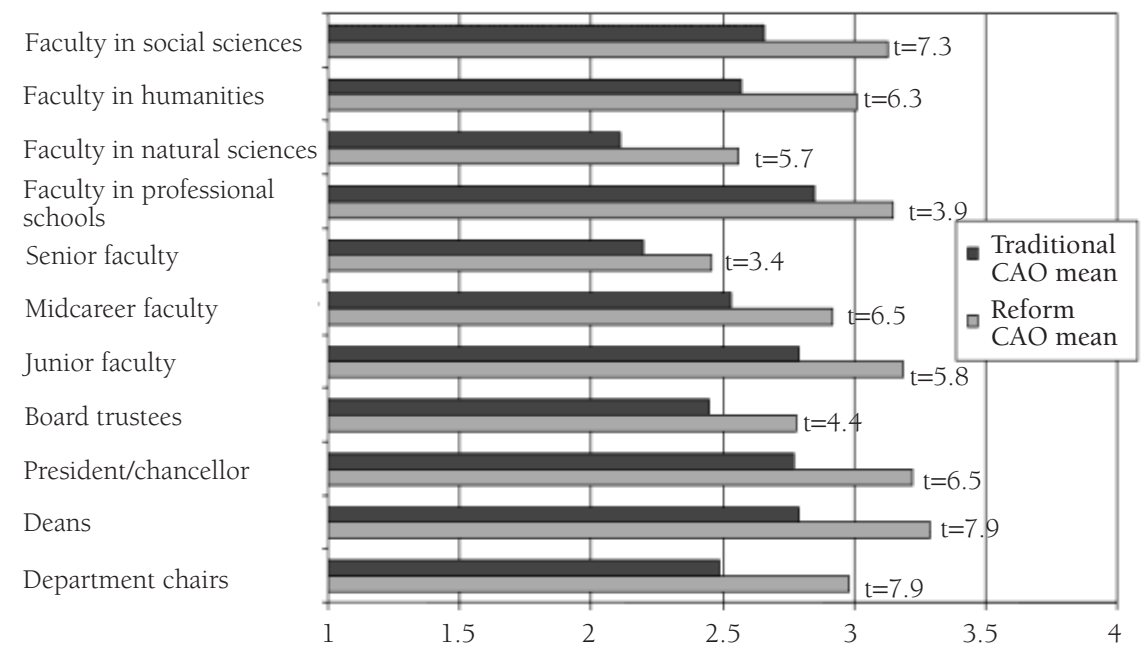

Note: Response scale: 1 = opposed, 2 = neutral, $3=$ supportive, 4 = very supportive. All $t$-tests are statistically significant $(p<0.001)$.

game, with its constant stress of recruiting faculty researchers and publishing demands, is more of a concern for the doctoral/research universities than the others. Moreover, doctoral institutions had problems ensuring a common definition of scholarship and standards that are well understood and enforced across disciplines. For baccalaureates (likely smaller institutions), implementation across disciplines, research orientation of faculty, and mission drift are less barriers to encouraging multiple forms of scholarship than the likely stress of teaching and advising load.

We know from previous work on faculty work life that master's institutions, the majority being public state colleges, struggle with frequent shifts in priorities and leadership, and many faculty unions take on a defensive stance to any reforms initiated by the administration (Arnold, 2000). In a similar vein, master's colleges in this study found the political nature of the promotion and tenure process, union resistance, and changes in priorities to be significant barriers. Yet it is interesting to note that there is a higher percentage of master's' colleges than other types that have implemented the Boyer reform. This goes against the perception that the Boyer framework is 
mostly used by campuses at either end of the Carnegie classification. Although a majority of all campuses initiated the reforms studied here, these reforms seem to have been particularly picked up by the institutions in the middle of the Carnegie classification: those with significant but not the highest teaching loads, likely aspiring to more and greater scholarship, and with a firm commitment to their teaching and service missions.

These findings suggest that some catalysts and barriers are the same within each type but differ across institutional types. For example, the Boyer reforms were always intended to help research and doctoral institutions create a vehicle for valuing teaching and research more (Boyer, 1990; Glassick, Huber, and Maeroff, 1997; Huber, 2002); thus, it is not surprising that values prioritizing research still remain and act as a barrier within these institutions. The Boyer reform is one lever for change but not a panacea for this problem. Until graduate education and disciplinary associations emphasize newer forms of scholarship as legitimate and scholarly, these problems will remain. At baccalaureates, the reform was intended to encourage more faculty involvement in any form of scholarship, including inquiry into teaching and learning, application, and integration despite very heavy teaching and advising responsibilities (Brailow, 2005; Braskamp, 2003; Berberet, 2002). The Boyer reform is one way to encourage this work, perhaps with other supports like release time, course reduction, and professional development.

Thus, the goal for provosts, deans, and department chairs implementing reforms to encourage multiple forms of scholarship should be to identify the key stresses and barriers to productive faculty work overall and to initiate the Boyer reform in ways that help to address them. For example, if it becomes next to impossible to ensure that a consistent definition of scholarship is used across a large doctoral institution, why not let each department develop its own disciplinary definition of each of the four forms of scholarship and methods for evaluation? This strategy met significant success at South Dakota State University (Peterson and Kayongo-Male, 2005). If reforms initiated by the administration are suspect, they might be allowed to percolate first within the faculty senate or union, which should have the ability to shape them, as was the case at St. Norbert College and Franklin College (Brailow, 2005; Zahorski, 2005).

Second, across all institutional types, reforming faculty reward systems to encourage multiple forms of scholarship positively influenced acceptance of this work within academic cultures. The findings also suggest that campus constituencies at reform institutions are more supportive of the broader view of scholarship. While it is not clear whether this greater acceptance existed before the reform or was a product of its campuswide implementation and results, at minimum it seems reasonable to assume that making the reforms will create greater visibility for and discussion around multiple forms of scholarship and that these efforts may result in greater support for the idea of multiple forms of scholarship across campus. The fact that 
reform campus CAOs were more likely to observe that over the past ten years their campus had developed a more nuanced definition of scholarship suggests a healthy conversation had occurred, one that can only benefit those involved in both traditional and alternative forms of scholarship.

The findings from this study also suggest important areas for future research for institutional researchers and nationwide studies of reward system change.

Areas for Institutional Research. It is important for individual campuses and their institutional researchers to study whether Boyer's reforms have changed academic cultures from the perspective of individual faculty careers. Huber's work (2004) examining pathfinders, or faculty who have pursued the scholarship of teaching, provides such an example. From a micro, or individual, career perspective, have faculty involved in the scholarship of application or integration found career progression and promotion any easier? Have departments made any strides in honoring multiple talents and appreciating different scholarly contributions such that individual faculty feel a difference in how their work is considered and valued? How does this differ by discipline? Finally, do campuses that make these reforms encourage faculty with plateaued careers into new directions? Campus and department case studies, individual faculty portraits, ethnography, and interviews are all methods well suited to these questions.

More than fifteen years after Boyer's reforms were proposed, it is also important for institutional researchers to study their own campuses' secondgeneration issues in institutionalizing a broader definition of scholarship, as was done at Portland State University (Rueter and Bauer, 2005), a campus well known for having made these reforms in the mid-1990s. What happens when new faculty with research orientations come to these institutions with a broader definition of scholarship? Do they change, or do they change the definition, or somewhere in the middle? Annual faculty surveys noting changes in faculty views of scholarship, records of changes in hiring, and annual profiles of the scholarship of recently tenured faculty might help to illuminate whether the campus continues to embrace or is moving closer toward a broader definition of scholarship in faculty roles and rewards.

Areas for Nationwide Study of Academic Reward System Change. On a macrolevel, it is important for institutional researchers, higher education faculty who study academic culture and reward systems, and researchers at higher education associations and think tanks to collaborate on nationwide studies. For example, studies need to be done across state systems of higher education and within specific institutional types to discover whether changes in reward systems have significant effects outside faculty work life and satisfaction. For example, on research and doctoral campuses that have made major strides in encouraging the scholarship of teaching, do students see any difference in terms of the quality of their classes, their own learning, or development? In other words, does more time spent on the 
scholarship of teaching (which may have been shifted in part because of a reformed reward system) result in more learning for students? Have the surrounding communities found faculty more immersed in community problems, and has this greater commitment resulted in desired outcomes?

Across campuses, we need to examine which campuses virtually adopted the reforms (Birnbaum, 2000) versus which ones seem to be making promotion and tenure decisions and resource allocations with a broader definition of scholarship in mind. Scholars of organizational change in higher education need to understand better why campuses went in these different directions. Finally, how has the phenomenon of "striving colleges," and academic ratcheting, wherein colleges compete for U.S. News and World Report rankings (O'Meara and Bloomgarden, 2005), influenced the implementation of a broader definition of scholarship in different sectors of higher education (for example, liberal arts colleges versus research universities), especially since 2001, as the marketplace has become more competitive? These are questions ripe for exploration that would benefit from collaboration between institutional researchers with campus-specific data and higher education research centers that conduct national trend studies on faculty and changes in faculty employment.

\section{Conclusion}

Encouraging multiple forms of scholarship in reward systems is not a panacea for all of the problems that we know exist within reward systems, such as the political nature of decisions, ambiguous standards, and sparse funding for merit. Also, the reforms discussed in this chapter will have different purposes and results across institutional types. However, according to the CAOs in this study, changing promotion and tenure language and institutional mission statements and providing flexible workload programs and incentive grants to encourage multiple forms of scholarship make a positive difference in beliefs about and acceptance of multiple forms of scholarship. Encouraging such multiple forms of scholarship has the potential for effecting change when implemented with a sensitivity to institutional cultures and constraints on faculty time. Further research is needed to explore the depth of change and the challenges and benefits to implementing these reforms in different institutional types.

\section{References}

Arnold, G. B. The Politics of Faculty Unionization: The Experience of Three New England Universities. Westport, Conn.: Bergin and Garvey, 2000.

Berberet, J. "The New Academic Compact." In L. A. McMillin and J. Berberet (eds.), The New Academic Compact: Revisioning the Relationship Between Faculty and Their Institutions. Bolton, Mass.: Anker, 2002.

Bergquist, W. H. Four Cultures of the Academy. San Francisco: Jossey-Bass, 1992. 
Birnbaum, R. How Colleges Work. San Francisco: Jossey-Bass, 1988.

Birnbaum, R. How Academic Leadership Works. San Francisco: Jossey-Bass, 1992.

Birnbaum, R. Management Fads in Higher Education. San Francisco: Jossey-Bass, 2000.

Blackburn, R. T., and Lawrence, J. H. Faculty at Work: Motivation, Expectation, Satisfaction. Baltimore: Johns Hopkins University Press, 1995.

Bolman, L. G., and Deal, T. E. Reframing Organizations: Artistry, Choice and Leadership. (2nd ed.) San Francisco: Jossey-Bass, 1997.

Boyer, E. Scholarship Reconsidered. Princeton, N.J.: Carnegie Foundation for the Advancement of Teaching, 1990.

Brailow, D. "A Question of Mission: Redefining Scholarship at Franklin College." In K. O'Meara and R. Eugene Rice (eds.), Faculty Priorities Reconsidered. San Francisco: Jossey-Bass, 2005.

Braskamp, L. Fostering Student Development Through Faculty Development: A National Survey of Chief Academic officers at Church-Related Colleges. Chicago: Loyola University, 2003.

Braxton, J., Luckey, W., and Holland, P. Institutionalizing a Broader View of Scholarship Through Boyer's Four Domains. San Francisco: Jossey-Bass, 2002.

Clark, B. R. The Academic Life: Small Worlds, Different Worlds. Princeton, N.J.: Carnegie Foundation for the Advancement of Teaching, 1987.

Diamond, R. M. "Instituting Change in Faculty Reward Systems." In R. M. Diamond and B. E. Adam (eds.), Recognizing Faculty Work: Reward Systems for the Year 2000. New Directions for Higher Education, no. 81. San Francisco: Jossey-Bass, 1993.

Diamond, R. M. Aligning Faculty Rewards with Institutional Mission: Statements, Policies, and Guidelines. Bolton, Mass.: Anker, 1999.

Eckel, P., Green, M., Hill, B., and Mallon, W. On Change III: Taking Charge of Change: A Primer for Colleges and Universities. Washington, D.C.: American Council on Education, 1999.

Finnegan, D. E., and Gamson, Z. F. "Disciplinary Adaptations to Research Culture in Comprehensive Institutions." Review of Higher Education, 1996, 19(2), 141-177.

Fowler, F. Survey Research Methods. (2nd ed.) Thousand Oaks, Calif.: Sage, 1993.

Glassick, C. E., Huber, M. T., and Maeroff, G. I. Scholarship Assessed: Evaluation of the Professoriate. San Francisco: Jossey-Bass, 1997.

Huber, M. "Faculty Evaluation and the Development of Academic Careers." In C. Colbeck (ed.), Evaluating Faculty Performance. San Francisco: Jossey-Bass, 2002.

Huber, M. T. Balancing Acts: The Scholarship of Teaching and Learning in Academic Careers. Washington, D.C.: American Association of Higher Education and the Carnegie Foundation for the Advancement for Teaching, 2004.

Kezar, A. J. Understanding and Facilitating Organizational Change in the Twenty-First Century: Recent Research and Conceptualizations. ASHE-ERIC Higher Education Report, vol. 28, no. 4. San Francisco: Jossey-Bass, 2002.

Kuh, G. D., and Pascarella, E. T. "What Does Institutional Selectivity Tell Us About Educational Quality?" Change, Sept.-Oct. 2004, pp. 53-58.

Kuh, G. D., and Whitt, E. J. The Invisible Tapestry: Culture in American Colleges and Universities. ASHE-ERIC Higher Education Report, vol. 1. San Francisco: Jossey-Bass, 1988.

Lynton, E. Making the Case for Professional Service. Washington, D.C.: American Association for Higher Education, 1995.

O’Meara, K. "Rewarding Faculty Professional Service." Working paper 19, New England Resource Center for Higher Education, 1997.

O'Meara, K. A. "Uncovering the Values in Faculty Evaluation of Service as Scholarship." Review of Higher Education, 2002, 26, 57-80. 
O'Meara, K. A. Effects of Encouraging Multiple Forms of Scholarship Nationwide and Across Institutional Types. In K. O'Meara and R. Eugene Rice (eds.), Faculty Priorities Reconsidered. San Francisco: Jossey-Bass, 2005a.

O'Meara, K. "Encouraging Multiple Forms of Scholarship in Faculty Reward Systems: Does It Make a Difference?" Research in Higher Education, 2005b, 46(5), 479-510.

O'Meara, K., and Bloomgarden, A. "Exploring the Nature and Impact of Striving." Unpublished manuscript, University of Massachusetts, 2005.

Peterson, C., and Kayongo-Male, D. "Ensuring Equity Across the Missions of a Land Grant University: South Dakota State University." In K. O'Meara and R. Eugene Rice (eds.), Faculty Priorities Reconsidered. San Francisco: Jossey-Bass, 2005.

Prince, G. S. Jr. "A Liberal Arts College Perspective." In T. Ehrlich (ed.), Civic Responsibility and Higher Education. Phoenix, Ariz.: Oryx Press, 2000.

Rice, R. E. Making a Place for the New American Scholar. Washington, D.C.: American Association for Higher Education, 1996.

Rice, R. E., and Sorcinelli, M. "Can the Tenure Process Be Improved?" In R. Chait (ed.), The Questions of Tenure. Cambridge, Mass.: Harvard University Press, 2002.

Rueter, J., and Bauer, T. "Identifying and Managing University Assets: A Campus Study of Portland State University." In K. A. O'Meara and R. E. Rice (eds.), Faculty Priorities Reconsidered. San Francisco: Jossey-Bass, 2005.

Ruscio, K. P. "The Distinctive Scholarship of the Selective Liberal Arts College." Journal of Higher Education, 1987, 58(2), 205-222.

Schein, E. H. Organizational Culture and Leadership. (2nd ed.) San Francisco: JosseyBass, 1992.

Tierney, W. G., and Bensimon, E. M. Promotion and Tenure: Community and Socialization in Academe. Albany: State University of New York Press, 1996.

Ward, K., and Wolf-Wendel, L. "Academic Life and Motherhood: Variations by Institutional Type." Paper presented at the Annual Conference of the Association for the Study of Higher Education, Portland, Ore., 2004.

Zahorski, K. "Redefining Scholarship: A Small Liberal Arts College's Journey." In K. O'Meara and R. E. Rice (eds.), Faculty Priorities Reconsidered. San Francisco: JosseyBass, 2005.

KERRYANN O'MEARA is assistant professor of higher education and program coordinator at the University of Massachusetts Amherst. 